\title{
Trend analysis of the international tourist services market
}

\author{
D. Skripnuk, K. Kikkas \& N. Didenko \\ St. Petersburg State Polytechnical University, Russia
}

\begin{abstract}
The paper presents a method of trend analysis of the international tourist services market. The method includes several stages of analysis. The first stage in the paper is a description of the indicators. The analysis was carried out on a selection of 56 countries for a period of 15 years. The quantitative assessment is performed with the following indicators: international tourist income, international tourist expenditure, international tourist arrivals and international tourist departures. The main attention in the paper is focused on the tourist flows of the developed and developing countries. The second stage is grouping of the countries in order to find the rank of the country on the international market of tourist services. Three groups of countries were formed. These groups have different trends in the sphere of tourist services. The analysis of the differences in the sphere of tourist services in various countries was carried out in the paper. The first group consists of the countries with high tourist activity. These countries can be characterized with high tourist income and expenditure per capita, large number of arrivals and departures and small trip duration. The second group is composed of the countries with low tourist activity. These countries can be characterized with low tourist income and expenditure per capita, small number of arrivals and departures per capita and large number of overnight stays. The third group consists of the countries with medium tourist activity. These countries can be characterized with medium tourist income and expenditure per capita, and small trip duration.

Keywords: international tourist services market, international tourist services market indicators, method of trend analysis.
\end{abstract}




\section{Introduction}

Tourism is the most profitable types of business in the world. According to the data of United Nations World Tourist Organization (UNWTO) in 2013 Travel and tourism accounted for 266 million jobs ( 1 in 11 all jobs in the world) and contributed $9.5 \%$ of global GDP (nearly US\$7 trillion), tourism accounts for $11 \%$ of the world's consumer spending and $5 \%$ of all tax revenues [1].

The existing definition of tourism can be combined into two groups. Some of the definitions are highly specialized and relate to some economic, social, legal and other aspects of tourism or its specific generic features. This definitions serve as a tool for performing some specific tasks (for example, the definition of tourism and tourist services for statistical purposes). The other conceptual or essential definitions show tourism as an integrated system. The essential definition of tourism is given, for instance, by the International Association of scientific experts in tourism (AIEST). According to the definition tourism is "a set of relations and events that occur during transfer of people and their stay outside of their permanent place of residence and work" [2]. The problems of development of the world tourist services market are being studied not only technically, say, in order to quantify the tourist flows, but also systematically, say, a research of influence of the tourist flows on the socio-economic development of the regions. The research of the trends in the international tourist services market are dedicated to the following topics: (1) the forms of tourist activities organization. For instance, Novelli et al. are researching networks, clusters and innovations in tourism on the basis of the British experience [3]; (2) the models for choosing of the tourist destinations - Seddighi and Theocharous, etc. [4]; (3) the socio-cultural assessment of ecosystem services in tourism [6]; (4) the assessment of the tourism development [7-9].

The contemporary case studies are focused on the elaboration of the principles of sustainable tourism development, which are to provide the balance between further development of tourism, international trade, economic interests on the one hand and environmental protection, protection of social and cultural values on the other.

Wunder [10] empirically proves the interdependence of ecotourism and economic incentives, as well as environmental liability and sustainability of tourism. The economic incentives are necessary for nature protection especially in some remote and poorly controlled areas, where the weak presence of state powers impedes the use of alternative instruments of environmental regulation. Using data from the Cuyabeno - the Wildlife Reserve in the Ecuadorian Amazon region, near the border with Colombia and Peru - Wunder empirically shows the interdependence of tourism, local benefits and preservation of the environment. There were distinguished three groups within the local population in Cuyabeno, and for each of these groups various types of participation in tourism were developed. These types are varying from partial employment in the tourist activities and up to having regular income from tourism. The quantitative evaluation of the local cash flows from tourism makes it possible to carry out comparative analysis of the structure of income, costs and impact on the 
economic development of the region in order to preserve the environment. The researcher comes to the conclusion that throughout the whole studied region tourism actually provided significant additional income. The main factors are the tourist attractiveness of the natural object, the degree of specialization of tourist activities, the complementary nature of the other productive activities, as well as the structure of incentives.

We suppose, that these factors of tourism sustainability can be applied also for development of the arctic tourism, which is the most intensively expanding segment within the tourist services market. The development of the arctic tourism should lie primarily within the notion of ecological responsibility. It should be pointed out, that the problem of quantitative assessment of the development of the arctic tourism is a poorly studied subject. The applied scientific research within the arctic tourism are mainly aimed at the possibilities of development of various kinds of the arctic tourism [7], the perspectives of the development of tourism in the region, related to the warming of the Arctic climate $[8,9]$, creating of the infrastructure for attracting tourists to the region.

A group of Canadian scientists (Dawson et al. [8]) drew attention to the prospects for the development of marine tourism in polar waters. Indeed the climatic changes and reduction of the ice cover open up new opportunities for navigation including tourist navigation. In turn, the increase of the vessel flow demands for development of the appropriate state regulatory systems and infrastructure development. The authors have found up that currently in Canada there is no special regulatory authority as well as no plan and no recommendations for the development of polar marine tourism present. All this is a considerable impediment to the growth of this segment of the market, which, however, has prospects of development.

An interesting look at the development perspectives for the polar tourism was suggested by a Finnish researcher Kaján [9]. In the article the author examines the experience of two Lapponian communities that are strongly dependent on the tourist flows. Among the factors, influencing the life of the local population Kaján selects climatic and non-climatic ones. All these factors in this or that way force the local population to adapt to rapidly changing conditions. The author says that climate warming can both positively and negatively affect the prospects of the regional tourism. On the one hand the traditional activities of the population is closely connected to the environmental conditions and natural resources, on the other hand the climatic changes can open up new prospects for attracting tourists. The important factor is the strengthening of international interest in the Arctic that facilitates the integration of the polar tourism in the global economy. Finally, the author stresses the need for sustainable Arctic tourism development as well as need for assistance in adapting of the local population to the changing conditions.

On the level of the applied scientific research in the sphere of arctic tourism, as we assume, the toolset elaboration for evaluation of the economic, ecological, social and political risks is needed. The toolset should also assess the possibilities of the development of the arctic territories, being quite unique objects that combine the economic-resource elements, the social, political and 
ecological elements. The specificity of different quantitative assessments of various development aspects of the arctic tourism as well as the aspects of the regional development can be based on the principles introduced in the article of Didenko and Skripnuk [11]. The impact of energy resources on social development in Russia.

The functional criteria of tourism services in terms of assessments [12, 13], preferences $[14,15]$ and factors $[16,17]$ are studied by researchers from various fields of knowledge. Baker and Crompton suggest a structure equations model that shows the dependence of the service quality factors and the satisfaction degree on the tourist motivation [14].

Bigne et al. explore the relationship of the consumer behavior evaluation and the tourist flows [12]. The authors empirically prove the role of tourist image as a key factor of tourist preferences and, finally, the factor that makes the tourist flows to increase.

Problems of classification of tourist regions are explored from the perspective of assessing greater attractiveness of the regions and the competitiveness of the regional tourist markets. For example, in the article [18] Vila et al. suggest the method for estimating the competitiveness of regional cluster centers with the approbation of the method on the data of Spain and Australia.

The alternative methods for the international tourist market segmentation were being developed. For instance, in the article [5] it is suggested that the method of clustering of the fuzzy data (BFMCM-FD) to be used in order to identify the most preferred tourist destinations. The method is applied on the basis of the 328 Chinese consumers that make up the four segments of tourist destinations in Western Europe.

\section{General information on the development of the international market of tourist services}

The tourist services market share grows every year within the service sector. The globalization of the tourist activities provides for emerging of new segments within the international tourist services market. The competition among operators is growing.

The world market of tourist services includes the market for accommodation services with prevailing share of hotels in the market, the market for transportation services where air transporting has a leading role and the market of tourist organizations, so called travel retail.

The world market of hotel services can be characterized by the following features. The countries with developing economies the number of hotels is higher, than in the developed countries.

According to the International Hotel and Restaurant Association [19] countries with developing economies become more attractive for hotel business. Despite of the lower share of hotels in the developed countries, the segment enjoys relatively higher proceeds. In 2009 the hospitality segment of the developed countries earned US\$263 billion, whereas the developing countries earned only US\$126 billion. The developed countries have higher prices on 
hospitality services which is related to higher standards of living and large share of business travelers. According to the Bloomberg index the highest prices for hotels services are in three cities. In Geneva the average cost of overnight stay is US\$308, in Dubai US\$273, in Kuwait US\$253 and US\$250 in Zurich (figures from 2014) [19].

The leading share of the international hospitality services market and the leading sales share is held by Marriott International Inc., who have an international network of American hotels. 2800 hotels of the Marriott brand name are situated in the US and other 66 countries of the world [20]. Hilton hotel network has the second largest market share. The network is mainly represented in North America, expanding to the Asia-Pacific region, the Middle East, Africa and Latin America.

The global air transportation market is characterized by the following features. According to the estimations of IATA (International Air Transport Association) [21] the air transport plays dominating role on the world market of transport services in transporting of tourists over long distances (over $500 \mathrm{~km}$.). An increase of passenger air transporting takes place in the developed countries as well as in the regions with developing markets. The greatest increase of passenger air transportation in 2010-2014 was in the Middle East. According to the IATA data the Middle East countries are the world leaders of the occupied passenger seats index $(81.1 \%)$, the lowest index values are in the African countries $(68.9 \%)$. The average European occupied seats index is $77.2 \%$ (as of 01.01.2014). The steady growth in passenger traffic in the Middle East countries can be explained with an increase of the number of business trips to the region. The substantial growth of passenger air transportation in 2013-2014 was also reported by the airlines of Europe and the Asia-Pacific region. The international passenger traffic growth is observed also in Russia. In Japan, to the contrary, the increasing of the internal demand for air transportation services takes place.

The leader in the market of air transportation services is Delta Air Lines, Inc. (United States). It is the largest airline in the world in three important criteria (the size of the fleet, the volume of passenger traffic ( $6 \%$ of the market) and the number of destinations). The demand for air transportation services is rising much faster than the demand for most other goods and services in the world. Since 1970 up to 2014 the volume of air traffic that is measured with revenue from passenger per kilometer (RPK) increased tenfold, while the world GDP for the same period increased 3-4 times [22].

The world market of tourist organizations is characterized by the vast number of intermediaries. The process of tourist services promotion to the end-user is indirect one, it doesn't imply their immediate interaction. During the promotion process tourist services are completed in the so-called tourist products. The leader on the world market of tourist organizations is TUI AG (Touristik Union International). It is a German tourist company, one of the Europe's largest travel companies with the world market share of $4.2 \%$ and the European market share of $13.8 \%$ (data of 2010) [20]. The large tourist organizations are Carlson Wagonlit Travel (CWT) - France, Thomas Cook Group plc (United Kingdom), 
JTB Corporation (Japan), Expedia Inc. (United States). Each of these companies has a world market share of above $3 \%$.

\section{The development indicators of the world tourist services market}

The development indicators of the world tourist services market are indicators that characterize: (1) the tourist flows; and (2) the cash flows on the world market of tourist services.

The key indicators of the tourist flows are number of arrivals (departures) and duration of stay. The cash flow indicators are tourist income (expenses). Tourism itself is a sophistically structured branch that includes a number of related branches that provide services connected to tourist activities.

In this study the tourist branch will mean a sophistically structured branch that has its own specific product, the so called complex service, or a tour, as well as some tourist goods. The complex tourist service has an immediate impact on social, cultural, educational and economic spheres within a given country and also on the international level. The set of tourist goods and services makes up the notion of "tourist product".

This view tourism as a sophistically structured branch determines also the features of researching of the impact of tourism on the international economics and on development of separate regions.

As indicators that evaluate the impact of international tourism on the world economy and separate regions one should consider the following ones: tourist income per capita (US\$), tourist expenses per capita (US\$), tourist arrivals per capita (number of trips), tourist departures per capita (number of trips), and duration of international overnight stays (average number of overnight stays).

The capacity of the tourist market is determined by the number of exits from the country and the number of arrivals to the country. Generating of the tourist flows is an import of tourist services, while reception and serving of foreign tourists within the country represents an export of international tourist services.

\section{The quantitative appraisal of the flows of the global tourist services market}

The quantitative appraisal of the flows of the global market of tourist services is conducted in terms of tourist flows and cash flows for 1998-2014. The calculations were carried out on the basis of the Euromonitor International statistics [20].

According to the UNWTO data, the number of international tourist arrivals has grown 4 times for the period 1975-2010. In 1975 there were registered 222 million arrivals, in 1990 there were already 457 million arrivals. The growth rate of the international tourist market has slowed down a bit in 1991, but already in 1992 the rapid growth resumed and made up 481 million arrivals and in 1993 the level of 500 million arrivals was reached. In 2010 there were registered 955 
million of international tourist arrivals. After 2010 the steady uptrend can be observed in tourism.

The leading countries in the terms of international arrivals are (the 2011 data, million arrivals): France (77.5), United States (59), China (54.2), Spain (52.4), Italy (45.4), Turkey (30.1), United Kingdom (29.3), Malaysia (25.1), Germany (24.9) and Mexico (22.3). Since the beginning of mass tourism exchanges up to now Europe can be especially distinguished. France is the leader for a long period with a considerable advantage. The region is very popular among the Europeans, Americans and Canadians. The second place is steadily the United States. Europe and America (primarily the North America) are the major tourist regions.

The leaders in terms of tourist departures (as of 2011, million departures): Germany (85.2), United States (66.5), United Kingdom (55.9), Russia (35.5), Hong Kong (32.7), China (31.7), France (24.5), Italy (20), the Netherlands (18.4) and Japan (16.8).

The fastest growing segment of the market are medium-term trips. Short-term visits serve mainly business purposes.

According to the UNWTO, the total number of tourist overnight stays in the world in the mid-1990's. amounted to 8.2 billion. The main share of about $70 \%$ accounted for domestic tourism.

The flow analysis of the international tourist services market in terms of income from international tourism was carried out. The international tourism income amounted to US\$906.3 billion by 2010. The international tourism expenditure amounted to US\$772.5 billion by 2010. A positive tourist balance is typical for the countries with currency inflow greater then expenditures for international tourism (US, France). A negative tourist balance is typical for the donor-countries of the international tourist market. These countries supply the international tourist market with numerous travelers (Germany, Japan, and United Kingdom).

The leaders in terms of total income from international tourism (as to 2011, billion US\$ per year): United States (124.7), Spain (53.2), France (48.1), China (43.0), Italy (40.9), United Kingdom (35.7), Germany (32.6), Australia (26.4), Austria (19.2) and Turkey (19.1).

The leaders in terms of total tourist spending (as to 2011, billion US\$ per year): United States (82.7), Germany (82.0), United Kingdom (64.1), China (45.95), France (36.4), Japan (30.8), Canada (27.8), Italy (26.1), Russia (20.5) and Netherlands (20.3).

The quantitative analysis of the flows in the international tourist services market was carried out both for developing and developed countries. The researched period is 2010-2013. The number of tourists and tourism revenues from international tourism is higher in the developed countries. The tourist arrivals in developing countries are rapidly catching up the tourist arrivals in developed countries. The tourist flows from China, India and Russia are growing. However the income from tourism will remain substantially higher in developed countries than in developing ones. This disparity will increase. The demand for domestic travel is higher in developing economies. Despite of 
the rapid growth of the domestic tourism market in developing countries, the tourist expense remain substantially higher in developed countries.

The geography of the world tourist flows over the past 20-30 years has a tendency to change. The analysis has shown that the development of tourism along the regions is uneven. The highest growth rates are expected in Asian and Pacific countries, while in Europe and America the growth will be below the world average. The highest tourist mobility is expected in the Netherlands, Germany, Great Britain, Canada and Japan. Europe is the major tourist region of the world, it remains to be the leader, despite its constantly decreasing share of tourist arrivals: $1970-68.2 \% ; 2000-57.7 \% ; 2010-51 \% ; 2020$ (forecast) $44.8 \%$. The European tourism has a pronounced intraregional character. In the interregional outbound tourist flow the United States are distinguished the most.

The average number of cash proceeds per arrival as also an interesting indicator that shows the differences in the development level of tourism in various countries. The world average value is US\$979 (2011). The lowest values of the indicator are in Ukraine - US\$293 and Russia - US\$466 (2011). The large range of the indicator can be observed within the top-10 tourist services exporting countries, and among other countries as well.

\section{Grouping of countries according to the rank on the international tourist services market}

Grouping of countries according to the rank on the international tourist services market is performed with the following indicators: tourist income per capita (US\$), tourist spending per capita (US\$), tourist arrivals per capita (number of trips), tourist departures per capita (number of trips), and total international overnight stays (average number of overnight stays). The analysis was carried out based on the statistical data of Euromonitor International for 2013. The analyzed sample includes 56 countries. According to the rank of the country on the international tourist services market three clusters were formed.

The first cluster includes Austria, Singapore, Sweden and Switzerland. These are the countries with high level of tourist activity. The countries are characterized with high income from tourism and high tourist expenses per capita; large number of arrivals and departures and small duration of trips.

The second cluster is represented by countries of tourist interest (China, Indonesia, Japan, South Korea, Thailand, Bulgaria, the Czech Republic, Hungary, Poland, Romania, Russia, Argentina, Mexico, Egypt, Morocco, Turkey, etc.). The countries are characterized with low income from tourism and low tourist expenses per capita; small number of both arrivals and departures per capita and large number of international overnight stays.

The third cluster includes Belgium, Finland, France, Germany, Greece, Italy, the Netherlands, Portugal, Spain, the UK. These are the countries with medium tourist activity. The countries of the cluster are characterized by medium values of income from tourism and tourist expenses per capita and a small length of trips. 


\section{Conclusion}

The trends of the international tourist services market were revealed. The world market of tourist services can be characterized by uneven tourist flows along the regions. The growth rate of income from tourism is substantially higher than those for tourist arrivals. The income from tourism grow faster in the developed countries, while the tourist arrivals have higher growth rate in the developing countries. The geography of the world tourist flows is changing. The rate of Europe in the international tourist arrivals declines, the tourist flows in the AsiaPacific countries are increasing.

Three groups of countries with different development of the tourist sphere were formed.

The factors of tourism sustainability were identified. They make it possible to keep balance between the further development of the tourist exchange, economic interests, environmental protection and protection of social and cultural values.

The prospects of the arctic tourism were identified. This direction of tourist activity is developing with high dynamics. The principles of quantitative appraisal for different aspects of development of the arctic tourism and arctic territories were proposed.

\section{Acknowledgement}

This paper is based on research carried out with the financial support of the grant of the Russian Scientific Foundation (Project No. 14-38-00009), St. Petersburg Polytechnic University.

\section{References}

[1] The website of UNWTO. http://www2.unwto.org/.

[2] The site of the International Association of scientific experts in tourism (AIEST). http://www.aiest.org/.

[3] Novelli, M., Schmitz, B. \& Spencer, T. Networks, clusters and innovation in tourism: A UK experience. Tourism Management. Volume: 27. Issue: 6. Pages: 1141-1152. DOI: 10.1016/j.tourman.2005.11.011. Published: Dec 2006.

[4] Seddighi, HR \& Theocharous, AL. A model of tourism destination choice: a theoretical and empirical analysis. Tourism Management. Volume: 23. Issue: 5. Pages: 475-487. Article Number: PII S0261-5177(02)00012-2. Published: Oct 2002.

[5] D’Urso, P., Disegna, M., Massari, R. \& Prayag, G. Bagged fuzzy clustering for fuzzy data: An application to a tourism market. KnowledgeBased Systems. Volume: 73. Pages: 335-346. DOI: 10.1016/j.knosys.2014.10.015. Published: Jan 2015.

[6] Iniesta-Arandia, I., Garcia-Llorente, M., Aguilera, PA., Montes, C. \& Martin-Lopez, B. Socio-cultural valuation of ecosystem services: uncovering the links between values, drivers of change, and human well- 
being. Ecological Economics. Volume: 108. pp. 36-48. DOI: 10.1016/j.ecolecon.2014.09.028. Published: Dec 2014.

[7] Stewart, EJ., Howell, SEL., Draper, D., Yackel, J. \& Tivy, A. Sea ice in Canada's Arctic: Implications for cruise tourism. Arctic. Volume: 60. Issue: 4. Pages: 370-380. Published: Dec 2007.

[8] Dawson J., Johnston M.E. \& Stewart E.J. Governance of Arctic expedition cruise ships in a time of rapid environmental and economic change // Ocean \& Coastal Management. Vol. 89. pp. 88-89. March 2014.

[9] Kaján, A. Arctic Tourism and Sustainable Adaptation: Community Perspectives to Vulnerability and Climate Change // Scandinavian Journal of Hospitality and Tourism. Vol. 14. Issue 1. pp. 60-79. January 2014.

[10] Wunder, S. Ecotourism and economic incentives - an empirical approach. Ecological Economics. Volume: 32. Issue: 3. Pages: 465-479. DOI: 10.1016/S0921-8009(99)00119-6 Published: Mar 2000.

[11] Didenko N. \& Skripnuk D. The impact of energy resources on social development in Russia. WIT Transactions on Ecology and the Environment, Vol. 190, WIT Press, ISSN 1743-3541. 2014.

[12] Bigne, JE, Sanchez, MI \& Sanchez, J. Tourism image, evaluation variables and after purchase behaviour: inter-relationship. Tourism Management. Volume: 22. Issue: 6. Pages: 607-616. DOI: 10.1016/S02615177(01)00035-8. Published: Dec 2001.

[13] Petrosillo, I., Zurlini, G., Corliano, M. E., Zaccarelli, N. \& Dadamo, M. Tourist perception of recreational environment and management in a marine protected area. Landscape and Urban Planning. Volume: 79. Issue: 1. Pages: 29-37. DOI: 10.1016/j.landurbplan.2006.02.017. Published: Jan 152007.

[14] Baker, DA \& Crompton, JL Quality, satisfaction and behavioral intentions. Annals of Tourism Research. Volume: 27. Issue: 3. Pages: 785-804. DOI: 10.1016/S0160-7383(99)00108-5. Published: Jul 2000.

[15] Sorensen, F. \& Jensen, JF. Value creation and knowledge development in tourism experience encounters. Tourism Management. Volume: 46. Pages: 336-346. DOI: 10.1016/j.tourman.2014.07.009. Published: Feb 2015.

[16] Chen, CF, Tsai, D How destination image and evaluative factors affect behavioral intentions? Tourism Management. Volume: 28. Issue: 4. Pages: 1115-1122. DOI: 10.1016/j.tourman.2006.07.007. Published: Aug 2007.

[17] Castro CB, Armario, EM \& Ruiz, DM. The influence of market heterogeneity on the relationship between a destination's image and tourists' future behavior. Tourism Management. Volume: 28. Issue: 1. Pages: 175-187. DOI: 10.1016/j.tourman.2005.11.013. Published: Feb 2007.

[18] Vila, TD, Darcy, S \& Gonzalez, E. Competing for the disability tourism market. A comparative exploration of the factors of accessible tourism competitiveness in Spain and Australia. Tourism Management. Volume: 47. Pages: 261-272. DOI: 10.1016/j.tourman.2014.10.008. Published: Apr 2015. 
[19] International Hotel and Restaurant Association. The voice of the hospitality industry worldwide. http://ih-ra.com/industry-news/memberspress-release/.

[20] The database of Euromonitor International. www.portal.euromonitor.com.

[21] The international air transport Association (IATA).http://www.iata.org.

[22] Profitability and the air transport value chain. http://www.iata.org/ publications/economic-briefings/profitability-and-the-air-transport-value \%20chain.pdf. 2013. 